\title{
Sex Difference Among Patients with Unprotected Left Main Coronary Artery Disease Undergoing Percutaneous Coronary Intervention in Northern China
}

\author{
Yongxin Wang, MD,${ }^{1}$ Zhiqiang Yang, $\mathrm{MD},{ }^{1}$ Yonggang Yuan, $\mathrm{MD},{ }^{2}$ Zesheng $\mathrm{Xu}, \mathrm{MD}^{2}$ \\ ${ }^{1}$ Department of Medicine, Cangzhou Medical College, Cangzhou, Hebei, China; ${ }^{2}$ Department of Cardiology, Cangzhou Central \\ Hospital, Cangzhou, Hebei, China
}

\section{ABSTRACT}

Background: Unprotected left main coronary artery (ULMCA) disease is associated with high mortality and morbidity. The aim of this study is to investigate the efficacy of percutaneous coronary intervention (PCI) on gender-specific patients with ULMCA in the Chinese population and provide a basis for further treatment of PCI in ULMCA disease.

Methods: 173 patients (female, $\mathrm{N}=52$; male, $\mathrm{N}=121$; mean age $=61.02 \pm 7.95$ ) with ULMCA disease, who underwent PCI between January 2010 and December 2014, were investigated in our study. The mean follow-up time was $23.8 \pm 7.3$ months. The baseline clinical characteristics, coronary angiography (CAG) and PCI procedures, and in-hospital and follow-up outcomes of gender-specific patients were evaluated.

Results: There were no statistically significant differences in baseline clinical characteristics with the exception of body weight, height, and smoking indexes between women and men. During PCI procedure, femoral artery puncture was more preferred in women than men $(P<.05)$, whereas radial artery puncture was more preferred in men than women $(P<.05)$. The characteristics of CAG and PCI procedures (except puncture path) were showed with no markedly difference between women and men. The incidences of MACCEs in male patients during the in-hospital and follow-up periods were slightly higher than those of the female patients although with no statistical differences.

Conclusion: In northern China, the incidence of ULMCA disease in men is likely to be higher than in women, whereas PCI for ULMCA disease shows similarly favorable outcomes in women as well as in men. During the PCI procedure, femoral artery puncture in women and radial artery puncture in men are recommended.

\section{INTRODUCTION}

Unprotected left main coronary artery (ULMCA) disease, belonging to left main coronary artery disease (LMCAD),

Received April 1, 2017; accepted April 10, 2018.

Correspondence: Zesheng Xu, Department of Cardiology, Cangzhou Central Hospital, No.16 Xinhua West Road, Cangzhou, Hebei 061001, China; +8613333376980 (e-mail: xuzesheng881@163.com). is associated with high mortality and morbidity [Caracciolo 1995; Fajadet 2012]. It is defined as the absence patent of bypass grafts to either the left anterior descending or the left circumflex coronary artery, which could be found in 4 percent to 6 percent of all patients under $\neg$ going coronary angiography (CAG) [Proudfit 1967; Chieffo 2006; Ragosta 2006].

As the technical evolution of percutaneous coronary intervention (PCI) with drug-eluting stents (DES) and aggressive antiplate-let therapy, PCI appears not only to be reserved for patients with poor surgical indication, but also a safe and effective method for ULMCA disease when patients are carefully selected [Eagle 2004]. Patients with ULMCA disease who have low risk for procedural complications and increased risk of adverse surgical outcomes are the candidates for PCI (class IIa) in American College of Cardiology (ACC)/American Heart Association (AHA)/Society for Cardiovascular Angiography and Interventions (SCAI) focused guidelines [Levine 2013]. Previous study of a nonrandomized registry comparing PCI and coronary artery bypass graft (CABG, a standard care for ULMCA) showed with similar results of patients with ULMCA undergoing PCI, even patients with PCI had a greater proportion of high-risk in the background [Lee 2006].

Sex difference could influence the dissection of coronary artery. Even with same body surface area, the coronary artery including left main coronary artery in women is much thinner than that in men [Herity 2003]. Female patients with coronary heart diseases are more easily accompanied with risk factors. Sudden death could occur with approximately $2 / 3$ of female patients with coronary heart diseases without any symptoms [Mosca 2007]. However, estrogen with the protective effects of hemangiectasis and improved blood flow on angiocarpy has been found in previous studies [Haynes 2000; Manson 2007]. Our aim in the study is to investigate the efficacy of PCI on gender-specific patients with ULMCA disease in the ethnic Han population of northern China and provide the basis for further therapy of PCI in ULMCA disease with different sex.

\section{MATERIALS AND METHODS}

Subjects: Patients with ULMCA disease who underwent PCI from January 2010 to December 2014 were investigated in Cangzhou Central Hospital. Patients were included if all the following criteria were met: (1) patients were diagnosed 
Table 1. Baseline clinical characteristics of the 173 patients

\begin{tabular}{|c|c|c|c|}
\hline Baseline clinical characteristics & $\begin{array}{l}\text { Women } \\
(\mathrm{N}=52)\end{array}$ & $\begin{array}{c}\text { Men } \\
(N=121)\end{array}$ & $P$ \\
\hline Ages (years) & $60.52 \pm 6.65$ & $61.24 \pm 8.47$ & .586 \\
\hline Weight (kg) & $67.84 \pm 11.18$ & $76.17 \pm 9.43$ & .001 \\
\hline Height (cm) & $158.82 \pm 7.12$ & $170.53 \pm 5.49$ & .000 \\
\hline Body mass index $\left(\mathrm{kg} / \mathrm{m}^{2}\right)$ & $25.55 \pm 2.86$ & $26.71 \pm 3.76$ & .163 \\
\hline \multicolumn{4}{|l|}{ Risk factors for CVD (N,\%) } \\
\hline Hypertension & $32(61.5 \%)$ & $66(54.5 \%)$ & .395 \\
\hline Diabetes mellitus & $13(25.0 \%)$ & $21(17.6 \%)$ & .246 \\
\hline Hyperlipidemia & $4(7.7 \%)$ & $5(4.1 \%)$ & .553 \\
\hline Family history of $\mathrm{CHD}$ & $13(23.1 \%)$ & $25(20.7 \%)$ & .527 \\
\hline Smoker & $8(15.4 \%)$ & $60(49.6 \%)$ & .000 \\
\hline \multicolumn{4}{|l|}{ Anamnesis (N,\%) } \\
\hline MI history & $6(11.5 \%)$ & $7(5.8 \%)$ & .317 \\
\hline $\mathrm{PCl}$ history & $10(19.2 \%)$ & $19(15.7 \%)$ & .569 \\
\hline CABG history & $0(0)$ & $4(3.3 \%)$ & .438 \\
\hline \multicolumn{4}{|l|}{ Auxiliary examination } \\
\hline$c \operatorname{Tnl}(\mathrm{ng} / \mathrm{L})$ & $5.13 \pm 12.50$ & 5. 15.42 & .831 \\
\hline LVEF (\%) & $61.58 \pm 10.17$ & $63.00 \pm 9.34$ & 0.472 \\
\hline
\end{tabular}

$\mathrm{PCl}$ : percutaneous coronary intervention; CVD: cardiovascular disease; CHD: coronary heart disease cardiac; cTnl: troponin I; LVEF: left ventricular ejection fraction.

with ULMCA identified by CAG; (2) patients with hemodynamic instability (emergency indication); (3) patients refused to receive $\mathrm{CABG}$ or had high perioperative risks for $\mathrm{CABG}$. The performance of PCI needed to be considered of coronary anatomy, patients' condition, risks for surgery, and hemodynamic indication by both interventional cardiologists and cardiac surgeons. Patients were excluded if one or more of the following criteria were met: (1) intolerance to antiplatelet drug or allergy to aspirin, Clopidogrel; (2) severe hepatic and renal dysfunction or allergy to contrast medium; (3) hemorrhagic disorder; (4) malignancies; (5) contraindica $\neg$ tion to surgical treatment. The study was approved by the institutional review board of Cangzhou Central Hospital. Written informed consent was obtained from each patient before the surgical procedures and for the use of personal information for research purposes.

PCI procedure and medical treatment: PCI procedure for ULMCA was conducted by traditional techniques [Yin 2015]. Preoperatively, all patients were treated with $300 \mathrm{mg}$ oral aspirin and $600 \mathrm{mg}$ oral Clopidogrel. A maintenance dose of 100 $\mathrm{mg} /$ day aspirin and $75 \mathrm{mg} /$ day Clopidogrel were performed during surgery. Unfractionated heparin with 70 units to 100 units per $\mathrm{kg}$ was administrated during the surgery. After PCI, all patients received $100 \mathrm{mg}$ /day to $300 \mathrm{mg}$ /day aspirin for one month. Antiplatelet regimen included lifetime aspirin of $100 \mathrm{mg} /$ day if no contraindications were present and $75 \mathrm{mg} /$
Table 2. CAG and $\mathrm{PCl}$ procedures profiles among patients $(\mathrm{N}=173)$

\begin{tabular}{|c|c|c|c|}
\hline Factors & $\begin{array}{l}\text { Women } \\
(\mathrm{N}=52)\end{array}$ & $\begin{array}{c}\text { Men } \\
(\mathrm{N}=121)\end{array}$ & $P$ \\
\hline \multicolumn{4}{|l|}{ Puncture path (N, \%) } \\
\hline Femoral artery & $19(36.5 \%)$ & $26(21.5 \%)$ & .039 \\
\hline Radial artery & $33(63.5 \%)$ & $95(78.5 \%)$ & .039 \\
\hline \multicolumn{4}{|l|}{ Target vascular lesions } \\
\hline Diameter (mm) & $2.45 \pm 0.61$ & $2.65 \pm 0.78$ & .137 \\
\hline Length (mm) & $9.35 \pm 3.76$ & $9.79 \pm 4.35$ & .488 \\
\hline Degree of stenosis (\%) & $71.50 \pm 20.49$ & $74.02 \pm 20.02$ & .453 \\
\hline \multicolumn{4}{|l|}{ Site of lesion $(\mathrm{N}, \%)$} \\
\hline Ostium & $14(26.9 \%)$ & $30(24.8 \%)$ & .768 \\
\hline Shaft & $12(23.1 \%)$ & $24(19.8 \%)$ & .630 \\
\hline Distal bifurcation & $26(50.0 \%)$ & $67(55.4 \%)$ & .516 \\
\hline \multicolumn{4}{|l|}{ Number of vessels intervened $(\mathrm{N}, \%)$} \\
\hline Single vessel (LM alone) & $6(11.5 \%)$ & $13(10.7 \%)$ & .878 \\
\hline \multicolumn{4}{|l|}{ Multivessel (N, \%) } \\
\hline (a) LM + 1 additional vessel & $11(21.2 \%)$ & $32(26.4 \%)$ & .460 \\
\hline (b) LM +2 additional vessels & $18(34.6 \%)$ & $34(28.1 \%)$ & .391 \\
\hline (c) $L M+3$ additional vessels & $17(32.7 \%)$ & $42(34.7 \%)$ & .797 \\
\hline \multicolumn{4}{|l|}{$\mathrm{PCl}$ technique $(\mathrm{N}, \%)$} \\
\hline Single stent crossing over LCX & $31(59.6 \%)$ & $67(55.4 \%)$ & .606 \\
\hline V-stenting & $0(0)$ & $2(1.7 \%)$ & .875 \\
\hline Crush-stenting & $6(11.5 \%)$ & $17(14.0 \%)$ & .656 \\
\hline Culottes-stenting & $0(0)$ & $1(0.8 \%)$ & 1.000 \\
\hline Kissing balloon & $9(17.3 \%)$ & $21(17.4 \%)$ & .994 \\
\hline \multicolumn{4}{|l|}{ Type of stent (N, \%) } \\
\hline Bare metal stent & $0(0)$ & $0(0)$ & \\
\hline Drug-eluting stents & $52(100 \%)$ & $121(100 \%)$ & \\
\hline Stents diameter $(\mathrm{mm})$ & $3.31 \pm 0.44$ & $3.42 \pm 0.54$ & .148 \\
\hline Total stents length (mm) & $23.12 \pm 7.27$ & $23.52 \pm 7.60$ & .783 \\
\hline Numbers of stents & $1.12 \pm 0.32$ & $1.16 \pm 0.41$ & .515 \\
\hline \multicolumn{4}{|l|}{ Complication (N, \%) } \\
\hline Pseudoaneurysm & $2(3.8 \%)$ & $1(0.8 \%)$ & .447 \\
\hline In-stent restenosis & $0(0)$ & $1(0.8 \%)$ & 1.000 \\
\hline Subacute thrombus & $0(0)$ & $1(0.8 \%)$ & 1.000 \\
\hline Infection in puncture site & $0(0)$ & $0(0)$ & \\
\hline Local hematoma in puncture site & $2(3.8 \%)$ & $0(0)$ & .163 \\
\hline
\end{tabular}

LM: left main coronary artery; PCl: percutaneous coronary intervention.

day of Clopidogrel for at least 12 months beginning from one month after surgery.

Assessment and clinical follow-up: Clinical follow-up via office visits or telephone contact was scheduled for all 
Table 3. In-hospital and follow-up outcomes between female and male patients $(\mathrm{N}=173)$

\begin{tabular}{lccc}
\hline & $\begin{array}{c}\text { Women } \\
(\mathrm{N}=52)\end{array}$ & $\begin{array}{c}\text { Men } \\
(\mathrm{N}=121)\end{array}$ & $P$ \\
\hline In-hospital (N,\%) & & & \\
MACCE & $3(5.8)$ & $1(0.8)$ & .152 \\
Cardiac death & $0(0)$ & $0(0)$ & \\
Noncardiac death & $1(1.9)$ & $0(0)$ & .663 \\
MI & $2(3.8)$ & $1(0.8)$ & .447 \\
Target-lesion revascularization & $0(0)$ & $0(0)$ & \\
Follow-up (N,\%) & & & \\
MACCE & $4(7.7)$ & $3(2.5)$ & .240 \\
Cardiac death & $1(1.9)$ & $0(0)$ & \\
Noncardiac death & $0(0)$ & $0(0)$ & .663 \\
MI & $0(0)$ & $0(0)$ & \\
Target-lesion revascularization & $3(5.8)$ & $3(2.5)$ & .528 \\
\hline
\end{tabular}

MACCE: major adverse cardiac and cerebrovascular events; MI: myocardial infarction.

patients within 36 months after hospital discharge. Major adverse cardiac and cerebrovascular events (MACCE) including all death, myocardial infarction (MI), and target-lesion revascularization were recorded. All deaths were considered cardiac unless an unequivocal non-cardiac cause could be established. MI was defined with recurrent symptoms of new ST-segment elevation or re-elevation of total creatine kinase of greater than three times the upper limit of normal value. Target-lesion revascularization was defined as a repeat percutaneous intervention of the target lesion or bypass surgery of the target vessel performed for restenosis or other complication of the target lesion, and the target lesion was defined as the treated segment from $5 \mathrm{~mm}$ proximal segments to the stent and to $5 \mathrm{~mm}$ distal segments to the stent [Cutlip 2007].

Statistical analysis: All data was analyzed by using SPSS software (version 16.0, SPSS, Inc., Chicago, IL). Continuous variables were expressed as means \pm standard deviation (SD) and analyzed with Student's t-test. Categorical variables were expressed as a number or percentage and analyzed with chi-square analysis. $P<.05$ was considered as statistically significant.

\section{RESULTS}

Baseline clinical data: A total of 173 patients (female, $\mathrm{N}=52$; male, $\mathrm{N}=121$; mean age $=61.02 \pm 7.95$ ) were enrolled in this study. Demographic and clinical characteristics of the patients are presented in Table 1. Body mass index and height were significantly lower in women than in men. Smokers were more frequently among men $(P<.05)$. There were no significant differences between women and men regarding other indexes such as age, risk factors (except smoking), and the results of auxiliary examination and histories of diseases.

The characteristics of CAG and PCI procedures: The characteristics of CAG and PCI procedures are presented in Table 2 . The femoral artery puncture was more preferred in women than men $(P<.05)$, whereas radial artery puncture was more preferred in men than women $(P<.05)$. No significant differences were observed regarding the target vascular lesions, site of lesion, numbers of vessels intervened, types and numbers of stents, PCI technique, stents diameter, total stents length, kissing balloon, or complications between women and men. Incidences of pseudoaneurysm and subacute hematoma from puncture sites were slightly higher in women than in men, although there was no statistical significance.

In-hospital and follow-up outcomes: As shown in Table 3, the following was reported: One female patient with a noncardiac cause of death, two female patients and one male patient with MI, and no patients with target-lesion revascularization during the in-hospital period. There was no significant difference with overall in-hospital MACCE incidence between women and men $(5.8$ percent versus 0.8 percent, $P=.152)$. The mean follow-up time was $23.8 \pm 7.3$ months. During the follow-up period, the following was reported: One female patient with a cardiac cause of death, and three female and three male patients with target-lesion revascularization. There was no statistical difference regarding the overall long-term MACCE incidence between women and men (7.7 percent versus 2.5 percent, $P=.240)$.

\section{DISCUSSION}

Our study demonstrated there was no statistical difference in baseline clinical data except the body mass, height, quantity, and smoking indexes. There is an imbalance in the quantity of patients with ULCMA disease between women and men. Soleimani et al [Soleimani 2009] showed that men were more likely than women to develop the ULCMA disease. In our study, the number of women (52/173) was markedly less than the number of male patients (121/173), which was consistent with the findings of Soleimani et al [Soleimani 2009]. The imbalance may be related to the protective effect of female estrogen on the cardiovascular system. The mean age of patients with ULCMA disease showed no difference between women and men $(60.52 \pm 6.65$ versus $61.24 \pm$ $8.47)$, which was consistent with previous domestic research [Xuebin 2014]. Nevertheless, Sheiban et al. [Sheiban 2010] found the age of female patients was significantly greater than male patients $(73.9 \pm 11$ versus $69.9 \pm 11.0)$. The discrepancy is probably owing to the different economic conditions, living standards, racial factors, and gonadal hormones between different countries.

During the PCI procedure, women were more likely to receive femoral artery puncture and men were more likely to receive radial artery puncture path in our study. The thinner radial arteries of women, which would lead to difficulty in surgery and postoperative care, are not recommended in PCI. On the contrary, the thicker radial arteries of men are appropriate for PCI. Previous studies have shown that the fatality rates of puncture paths between femoral artery and 
radial artery present no significant difference [Agostoni 2004; Ziakas 2004]. However, antispasmodic drugs are needed in the perioperative period with radial artery surgery.

Sex difference is a controversial factor in the prognosis of PCI. Kelsey et al. [Kelsey 1993] found that the short-term prognosis of PCI in women was worse than men. Narins et al [Narins 2006] showed that women had higher mortality of PCI and higher incidence of non-fatal MACCE than men in various age groups. The worse prognosis of PCI in women may be related to the complex factors such as the physical states, the thin and curved coronary artery, and complications [D'Ascenzo 2011; Benamer 2011]. Nevertheless, Singh et al [Singh 2008] found there was no significant difference between male and female patients regarding the fatality rate of PCI. Sheiban et al [Sheiban 2010] suggested that sex difference was not an independent predictive factor for patients with ULMCA, and PCI offered similarly favorable clinical results in women as well as in men. The conflicting results may be due to the varying usage of DES and the technical improvement of PCI [Jacobs 2002]. In our study, DES was used in all patients. The incidences of MACCEs during the in-hospital period and the follow-up period did not show any obvious differences between women and men, indicating that PCI had the similar therapeutic effect and prognosis on gender-specific patients with ULMCA disease.

Our study has some limitations. It was single-center, retrospective analysis which might affect the results due to unmeasured confounder. The small sample size might lead to a lack of statistically significant differences between women and men in these outcome measures. Finally, the follow-up time was relatively short for the analysis in the study.

\section{CONCLUSION}

In northern China, the incidence of ULMCA disease in men is likely to be higher than in women, while PCI for ULMCA shows similarly favorable clinical outcomes in women as well as in men. During the PCI procedure, femoral artery puncture in women and radial artery puncture in men are recommended.

\section{REFERENCES}

Agostoni P, Biondi-Zoccai GG, de Benedictis ML, et al. 2004. Radial versus femoral approach for percutaneous coronary diagnostic and interventional procedures; Systematic overview and meta-analysis of randomized trials. Journal of the American College of Cardiology 44:349-56.

Benamer H, Tafflet M, Bataille S, et al. 2011. Female gender is an independent predictor of in-hospital mortality after STEMI in the era of primary PCI: insights from the greater Paris area PCI Registry. EuroIntervention: journal of EuroPCR in collaboration with the Working Group on Interventional Cardiology of the European Society of Cardiology 6:1073-9.

Caracciolo EA, Davis KB, Sopko G, et al. 1995. Comparison of surgical and medical group survival in patients with left main equivalent coronary artery disease. Long-term CASS experience. Circulation 91:2335-44.

Chieffo A, Morici N, Maisano F, et al. 2006. Percutaneous treatment with drug-eluting stent implantation versus bypass surgery for unprotected left main stenosis: a single-center experience. Circulation 113:2542-7.
Cutlip DE, Windecker S, Mehran R, et al. 2007. Clinical end points in coronary stent trials: a case for standardized definitions. Circulation 115:2344-51.

D’Ascenzo F, Gonella A, Quadri G, et al. 2011. Comparison of mortality rates in women versus men presenting with ST-segment elevation myocardial infarction. The American journal of cardiology 107:651-4.

Eagle KA, Guyton RA, Davidoff R, et al. 2004. ACC/AHA 2004 guideline update for coronary artery bypass graft surgery: a report of the American College of Cardiology/American Heart Association Task Force on Practice Guidelines (Committee to Update the 1999 Guidelines for Coronary Artery Bypass Graft Surgery). Circulation 110:e340-437.

Fajadet J, Chieffo A. 2012. Current management of left main coronary artery disease. European heart journal 33:36-50b.

Haynes MP, Sinha D, Russell KS, et al. 2000. Membrane estrogen receptor engagement activates endothelial nitric oxide synthase via the PI3kinase-Akt pathway in human endothelial cells. Circulation research 87:677-82.

Herity NA, Lo S, Lee DP, et al. 2003. Effect of a change in gender on coronary arterial size: a longitudinal intravascular ultrasound study in transplanted hearts. Journal of the American College of Cardiology 41:1539-46.

Jacobs AK, Johnston JM, Haviland A, et al. 2002. Improved outcomes for women undergoing contemporary percutaneous coronary intervention: a report from the National Heart, Lung, and Blood Institute Dynamic registry. Journal of the American College of Cardiology 39:1608-14.

Kelsey SF, James M, Holubkov AL, et al. 1993. Results of percutaneous transluminal coronary angioplasty in women. 1985-1986 National Heart, Lung, and Blood Institute's Coronary Angioplasty Registry. Circulation 87:720-7.

Lee MS, Kapoor N, Jamal F, et al. 2006. Comparison of coronary artery bypass surgery with percutaneous coronary intervention with drug-eluting stents for unprotected left main coronary artery disease. Journal of the American College of Cardiology 47:864-70.

Levine GN, Bates ER, Blankenship JC, et al. 2013. 2011 ACCF/AHA/ SCAI guideline for percutaneous coronary intervention: a report of the American College of Cardiology Foundation/American Heart Association Task Force on Practice Guidelines and the Society for Cardiovascular Angiography and Interventions. Catheterization and cardiovascular interventions: official journal of the Society for Cardiac Angiography \& Interventions 82:E266-355.

Manson JE, Allison MA, Rossouw JE, et al. 2007. Estrogen therapy and coronary-artery calcification. The New England journal of medicine 356:2591-602.

Mosca L, Banka CL, Benjamin EJ, et al. 2007. Evidence-based guidelines for cardiovascular disease prevention in women: 2007 update. Journal of the American College of Cardiology 49:1230-50.

Narins CR, Ling FS, Fischi M, et al. 2006. In-hospital mortality among women undergoing contemporary elective percutaneous coronary intervention: a reexamination of the gender gap. Clinical cardiology 29:254-8.

Proudfit WL, Shirey EK, Sones FM, Jr. 1967. Distribution of arterial lesions demonstrated by selective cinecoronary arteriography. Circulation 36:54-62.

Ragosta M, Dee S, Sarembock IJ, et al. 2006. Prevalence of unfavorable angiographic characteristics for percutaneous intervention in patients with unprotected left main coronary artery disease. Catheterization and cardiovascular interventions: official journal of the Society for Cardiac Angiography \& Interventions 68:357-62. 
Sheiban I, La Spina C, Cavallero E, et al. 2010. Sex-related differences in patients undergoing percutaneous unprotected left main stenting. EuroIntervention: journal of EuroPCR in collaboration with the Working Group on Interventional Cardiology of the European Society of Cardiology 5:795-800.

Singh M, Rihal CS, Gersh BJ, et al. 2008. Mortality differences between men and women after percutaneous coronary interventions. A 25 -year, single-center experience. Journal of the American College of Cardiology 51:2313-20.

Soleimani A, Abbasi A, Kazzazi EH, et al. 2009. Prevalence of left main coronary artery disease among patients with ischemic heart disease: insights from the Tehran Angiography Registry. Minerva cardioangiologica 57:175-83.
Xuebin Wang LZ, Weiting Xu. 2014. The prognostic analysis of percutaneous coronary intervention in unprotected left main coronary artery diseases. Chinese Circulation Journal 29:74.

Yin Y, Xin X, Geng T, Xu Z. 2015. Clinical comparison of percutaneous coronary intervention with domestic drug-eluting stents versus off pump coronary artery bypass grafting in unprotected left main coronary artery disease. Int J Clin Exp Med 8:14376-82.

Ziakas A, Klinke P, Mildenberger R, et al. 2004. Comparison of the radial and femoral approaches in left main PCI: a retrospective study. J Invasive Cardiol 16:129-32. 